\title{
Viscoelastic Properties of Mineral-Filled Poly(lactic acid) Composites
}

\author{
Adriana Gregorova, ${ }^{1}$ Michal Machovsky, ${ }^{2}$ and Rupert Wimmer ${ }^{3}$ \\ ${ }^{1}$ Institute for Chemistry and Technology of Materials, Graz University of Technology, Stremayrgasse 9, 8010 Graz, Austria \\ ${ }^{2}$ Polymer Centre, Faculty of Technology, Tomas Bata University in Zlin, 76272 Zlin, Czech Republic \\ ${ }^{3}$ Institute for Wood Technology and Renewable Materials, University of Natural Resources and Life Sciences, Vienna, \\ Konrad Lorenz-Strasse 24, 3430 Tulln, Austria
}

Correspondence should be addressed to Rupert Wimmer, rupert.wimmer@boku.ac.at

Received 29 December 2011; Revised 27 February 2012; Accepted 1 March 2012

Academic Editor: Kibret Mequanint

Copyright ( $) 2012$ Adriana Gregorova et al. This is an open access article distributed under the Creative Commons Attribution License, which permits unrestricted use, distribution, and reproduction in any medium, provided the original work is properly cited.

Poly(lactic acid) was filled with $20 \mathrm{wt} \%$ of the three mineral fillers Mica, Zeolite, and Vansil, differing in the particle shape and surface area. Viscoelastic properties of unfilled and filled composites were investigated via dynamic mechanical analysis, while filler and fracture surface morphology of the composites was analysed through scanning electron microscopy. Results demonstrate the relationships between viscoelastic damping behaviour of filled PLA composites and the filler distribution in the PLA matrix. Both damping reduction and scanning electron microscope analysis revealed that Zeolite was better distributed in the poly(lactic acid) matrix than the other used fillers Mica and Vansil. The interfacial filler/matrix adhesion has again proved to be the key factor determining thermal and mechanical properties of reinforced composite material.

\section{Introduction}

Annual global production of polymers produced from petroleum has arrived at 150 million tons, with an expected growth of $5 \%$ p.a. [1]. Formation of fossil fuels has taken millions of years to form and due to extensive utilization their supply is now limited. In addition, the majority of the produced short-term goods made from plastic end up in landfills for indefinite periods of time. From this it is evident that the development of competitive renewable and biodegradable plastic materials is inevitable [2]. Poly(lactic acid), PLA, is at present one of the most promising biodegradable thermoplastics, also due to its commercial availability. Successful applications are seen in packaging, textile industry, in the biomedical field, and also in fiberreinforced composite manufacturing. To enhance competitiveness of PLA-based applications, the costs need to be optimized by using affordable filling materials. Due to its nucleating and reinforcing function mineral (inorganic) fillers such as talc, mica potassium titanate, calcium carbonate, calcium sulfate anhydrite, and hydroxyapatite are commonly used [3-8]. The influence of mineral fillers on thermal and mechanical properties of polymer composites depends on a number of factors, among filler concentration, filler particle size and shape, filler/polymer adhesion, filler dispersion in the polymer matrix, and the applied composite processing [8-11].

Dynamic mechanical analysis (DMA) is known as a technique that combines both mechanical and rheological characterization of polymer samples as a function of temperature, time, and frequency of the applied oscillating deformation force. Determination of relaxation phenomena enables us to evaluate glass transition, stress relaxation, dynamic fragility parameter, miscibility of the polymers, interfacial compatibility of the individual composite components, and filler effectiveness (in the case of filled composites) [12-16]. It is known that a good distribution of fillers in polymer matrices is essential for high performance of the composites [17-20]. We hypothesize that the state of filler dispersion in polymer matrices influences the viscoelastic properties. To address this hypothesis dynamic mechanical analysis was used as a method to predict filler distribution 
in polymer matrices. We assessed the state of dispersion in a PLA matrix of the mineral fillers Mica, Zeolite, and Vansil. The mineral fillers differed chemically as well as in their physical properties. However, the average particle size of $5 \mu \mathrm{m}$ was constant across the filler types. Interfacial compatibility between PLA and mineral filler was improved using 4,4' -methylenediphenyl diisocyanate (PLAg-MDI; [21]). Viscoelastic properties were analyzed by DMA, while morphology was investigated with scanning electron microscopy.

\section{Experimental}

2.1. Materials. PLA 7000D pellets obtained from NatureWorks LLC (Minnetonka, MN, USA) were used as matrix material. PLA had an average molecular weight $(\mathrm{Mw})$ of $140000 \mathrm{~g} \mathrm{~mol}^{-1}$, with a polydispersity index of 2.06 and a density of $1.22 \mathrm{~g} \mathrm{~cm}^{-3}$. Glass transition temperature and melting temperature of the native PLA resins were $60.5^{\circ} \mathrm{C}$ and $151.1^{\circ} \mathrm{C}$, respectively. PLA-g-MDI polymer matrix with $1 \mathrm{wt} \%$ of MDI was prepared according to Li and Yang [22]. Chemical formulas along with physical properties of the mineral fillers are shown in Table 1; the structural nature is seen in Figure 1.

MDI-modified PLA film composites were filled with $20 \mathrm{wt} \%$ of the mineral fillers Mica, Zeolite, or Vansil. The fixed concentration of $20 \mathrm{wt} \%$ was chosen as it was as a mechanical optimum, exhibiting also minimal brittleness. Composites were prepared through solution casting in chloroform followed by thermoforming (see Figure 2) [13].

2.2. Dynamic Mechanical Analysis (DMA). The viscoelastic properties of PLA and PLA/mineral filler films, the storage modulus $\left(E^{\prime}\right)$, loss modulus $\left(E^{\prime \prime}\right)$, and damping factor $\left(\tan \delta=E^{\prime \prime} / E^{\prime}\right)$ were both measured on a Netzsch DMA $242 \mathrm{C}$ operated in tension mode at $1 \mathrm{~Hz}$ frequency, within a temperature range between $-20^{\circ} \mathrm{C}$ and $120^{\circ} \mathrm{C}$, and a heating rate of $3^{\circ} \mathrm{C} / \mathrm{min}$. Strips were cut from the films at the size of $10 \times 6 \times 0.18 \mathrm{~mm}^{3}$.

From the values of storage moduli obtained at the glassy and rubbery regions, at a sweep frequency of $1 \mathrm{~Hz}$, the filler effectiveness (Factor $C$ ) in polymer matrix can be evaluated [23].

$$
\text { Factor } C=\frac{\left(E_{g}^{\prime} / E_{r}^{\prime}\right) \text { composite }}{\left(E_{g}^{\prime} / E_{r}^{\prime}\right) \text { PLA }}
$$

where, $E_{g}^{\prime}$ and $E_{r}^{\prime}$ are storage moduli determined at the glassy and rubbery regions, respectively.

The state of filler dispersion in the polymer matrix was determined by calculating the damping reduction (DR) [24], which is a ratio of the determined damping factors $(\tan \delta)$ of the neat and filled PLA-g-MDI composite types:

$$
\operatorname{DR}(\%)=\frac{(\tan \delta)_{\text {neat PLA-g-MDI }}-(\tan \delta)_{\text {filled PLA-g-MDI }}}{(\tan \delta)_{\text {neat PLA-g-MDI }}} \times 100
$$

2.3. Scanning Electron Microscopy. Surface morphology of the mineral fillers and the fracture surface morphology of the composites were investigated by scanning electron microscopy (TESCAN VEGA/LMU). Sample surfaces were sputtered with $\mathrm{Au} / \mathrm{Pd}$. The microscope was operated under high vacuum at an acceleration voltage of $5 \mathrm{kV}$.

\section{Results and Discussion}

3.1. Tensile Fracture Surface Analysis. SEM micrographs showed the different filler particle shapes in the composites (Figure 3). Mica was mostly platy, the zeolites had a blocky structure, and Vansil created fibrous aggregates.

Zeolite and Vansil were uniformly distributed in the PLA-g-MDI matrices indicating the efficiency in mixing the filler within the polymer matrix. In contrast, Mica was less distributed as it deposited on the bottom of the films. This deposition is connected to the applied solution casting method. The fracture surfaces of PLA-g-MDI filled with Mica and Vansil (Figures 3(a) and 3(c)) have shown voids between filler particles and the polymer matrix, which was taken as an evidence for poor adhesion. In opposite, SEM microscopy of PLA-g-MDI matrix filled with Zeolite particles indicated much better adhesion. Even with the Zeolite forming small agglomerates to some extent, fracture surfaces of this composite did not show voids or any sign of irregular distribution of the filler.

3.2. Viscoelastic Properties. Viscoelastic properties of composites $\left(E^{\prime}, E^{\prime \prime}\right.$, and $\left.\tan \delta\right)$ were detected through DMA to detect any changes in the sample in terms of mechanical, rheological, and thermal trends. Figures 4, 5, and 6 show storage moduli, loss moduli, and damping factors $(\tan \delta)$ as related to temperature.

All mineral filler types incorporated in the PLA-g-MDI matrices have raised the storage modulus of composites. The surfaces of these particles hold a number of hydroxyl groups that may have created agglomerates or caused poor dispersion in the hydrophobic PLA-g-MDI matrix. The differences in the obtained storage modulus values can be explained by the expressed chemical and physical differences among the filler types, that are, surface area, particle shape, hardness, and $\mathrm{pH}$ level $[17,18]$. All these factors are crucial for the resulting mechanical and thermal properties of the obtained composites. Filler effectiveness (Factor $C$, formula 1) indicating the composite reinforcing capacity can be seen in Table 2.

By definition, the unfilled polymer matrix film has a factor $C$ equal to 1 . Factor $C$ lower than 1 indicates a mechanical stiffening effect as well as a thermal stability contribution of the used filler. According to the obtained values mineral filler contributed to the PLA-g-MDI stiffness in the order Mica $>$ Zeolite $>$ Vansil.

Maximum loss moduli $\left(E^{\prime \prime}\right)$ of all PLA-g-MDI/mineral filler composites were higher than those obtained from unfilled PLA-g-MDI (Figure 5) indicating that the fillers contributed towards a greater viscous response due to the occurred friction between filler and polymer matrix. The 
TABLe 1: Physical properties of the used mineral fillers.

\begin{tabular}{|c|c|c|c|c|c|c|}
\hline Inorganic filler & Chemical formula & $\begin{array}{l}\text { Density } \\
\left(\mathrm{g} / \mathrm{cm}^{3}\right) \\
\end{array}$ & $\begin{array}{l}\text { Mohs } \\
\text { hardness }\end{array}$ & $\begin{array}{l}\text { Particle } \\
\text { shape }\end{array}$ & $\begin{array}{l}\text { Surface area } \\
\text { BET }\left(\mathrm{m}^{2} / \mathrm{g}\right)\end{array}$ & $\mathrm{pH}$ \\
\hline Mica SG ${ }^{\mathrm{a}}$ & ${ }^{\mathrm{d}} \mathrm{X}_{2} \mathrm{Y}_{4-6} \mathrm{Z}_{8} \mathrm{O}_{20}(\mathrm{OH}, \mathrm{F})_{4}$ & 2.9 & 2.5 & Platy & 7 & 11 \\
\hline Natural Zeolite ${ }^{\mathrm{b}}$ & $\left.\left(\mathrm{Ca}, \mathrm{K}_{2}, \mathrm{Na}_{2}, \mathrm{Mg}\right)_{4} \mathrm{Al}_{8} \mathrm{Si}_{40} \mathrm{O}_{96} \cdot 24 \mathrm{H}_{2} \mathrm{O}\right)$ & 2.3 & 2 & Blocky & 13 & 7 \\
\hline Vansil $^{\mathrm{c}}$ & $\mathrm{CaSiO}_{3}$ & 2.9 & 4.5 & Acicular & 4 & 9 \\
\hline
\end{tabular}

a Aspanger Bergbau und Mineralwerke.

b IFA, Tulln, Austria.

${ }^{c}$ Vansil, C. H. Erbslöh.

${ }^{\mathrm{d}} \mathrm{X}$ is $\mathrm{K}, \mathrm{Na}, \mathrm{Ca}, \mathrm{Ba}, \mathrm{Rb}$ or $\mathrm{Cs} ; \mathrm{Y}$ is $\mathrm{Al}, \mathrm{Mg}, \mathrm{Fe}, \mathrm{Mn} \mathrm{Cr}$, Ti or $\mathrm{Li} ; \mathrm{Z}$ is $\mathrm{Si}, \mathrm{Al}, \mathrm{Fe}^{3+}$ or Ti.

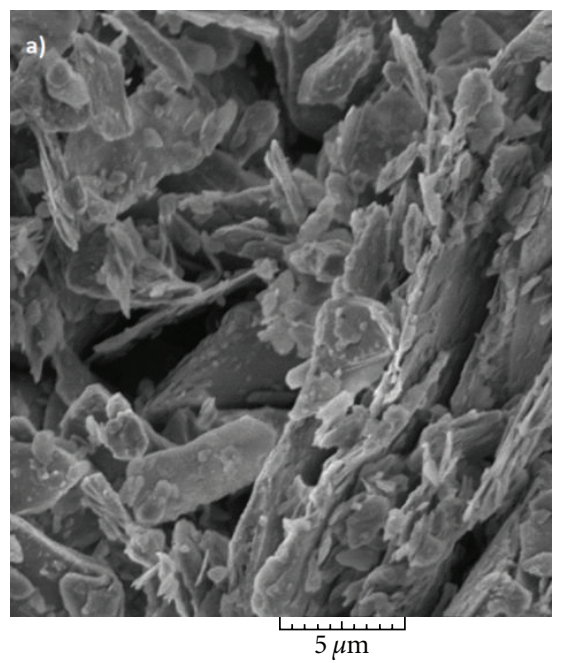

(a)

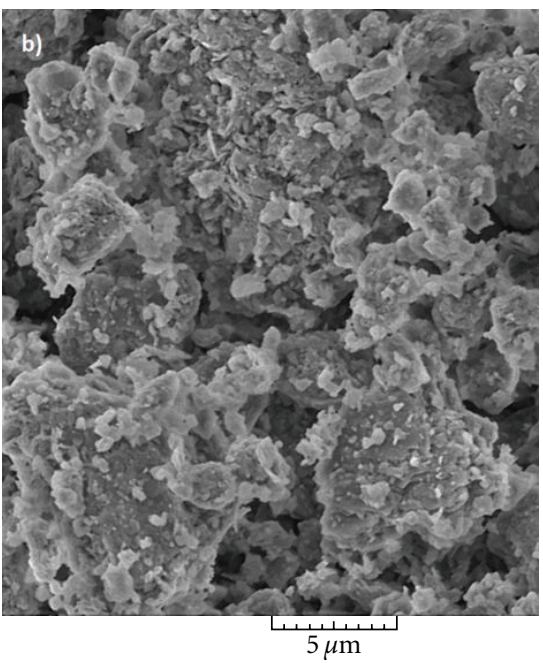

(b)

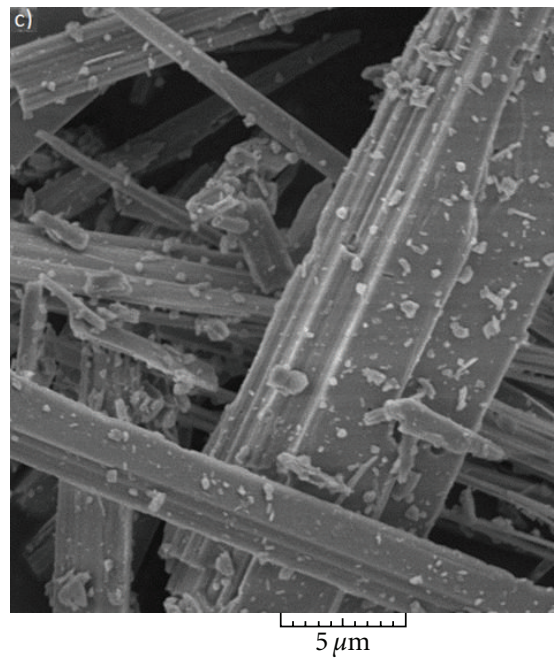

(c)

FIGURE 1: SEM micrographs of mineral fillers (a) Mica (monoclinic, tendency towards pseudohexagonal crystals), (b) Zeolite (silica, and alumina tetrahedrons), (c) Vansil (wollastonite; triclinic, with lamellar, compact, and fibrous aggregates).

values of glass transition temperature $\left(T_{g}\right)$, determined at the loss modulus peak temperature, reflect differences in the polymer chain segment mobility. The Mica filler has caused a $T_{g}$ shift of about $4^{\circ} \mathrm{C}$ towards higher temperatures, which is connected to a more restricted mobility of the PLA chains.

Damping $(\tan \delta)$ is highly sensitive to structural transformations of the polymers. The incorporation of fillers in polymer matrices usually broadens the $\tan \delta$ peak and changes its intensity depending on the actual damping mechanisms in composite. Composites with mineral filler in contrast to neat polymer show broader $\tan \delta$ peaks (Figure 6). The broadening of damping peak may be connected with the polymer chain arrangement that took place during the solution casting procedure. Mica and Vansil in contrast to Zeolite increased in a PLA-g-MDI matrix, an expressed composite damping. Additional damping in the particle-filled polymer composites may have occurred due to particle-particle friction, particle-polymer friction, induced thermal stresses near the interface, and the changed polymer morphology $[12,19,20]$. Table 3 shows the damping characteristics of PLA-g-MDI composites. The negative values of the damping reduction (PLA-g-MDI/Mica and PLA-g-MDI/Vansil) indicated the increase in damping. In accordance to the SEM analyses it is suggested that the increase in damping has occurred due to the breakdown of filler agglomerates. The lower $\tan \delta$ intensity of the PLAg-MDI/Zeolite composite indicates a better distribution of Zeolite prevalent in the PLA-g-MDI matrix.

\section{Conclusions}

Effect of $20 \mathrm{wt} \%$ of the mineral fillers Mica, Zeolite, and Vansil on the state of dispersion in PLA-g-MDI polymer matrix by the determination of viscoelastic properties as well as SEM microscopy was investigated. All used mineral fillers increased mechanical stiffness and have also changed the resulting molecular mobility of the PLA-g-MDI composites. The increase of storage modulus was accompanied with an increase of the loss modulus. However, the $\tan \delta$ intensity was different, depending on the present damping mechanism. With the obtained scanning electron microscope analyses it can be concluded that Zeolite was best dispersed in the PLAg-MDI matrix, compared to Mica and Vansil. Also, the values of damping reduction (DR) showed differences among the 


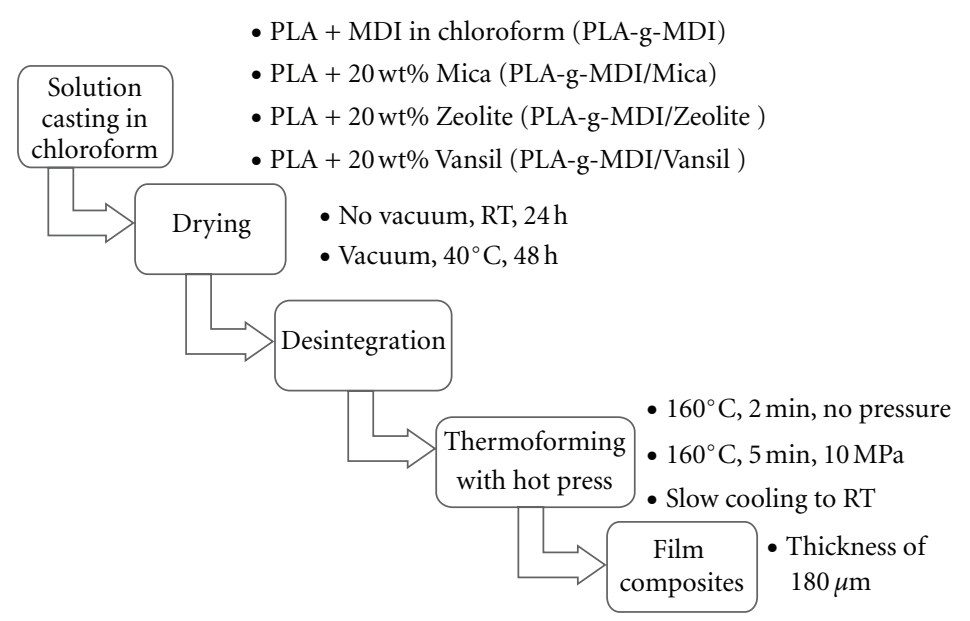

FIgURe 2: Preparation of mineral-filled PLA composites, compared with PLA modified with 4,4' -methylenediphenyl diisocyanate (MDI).

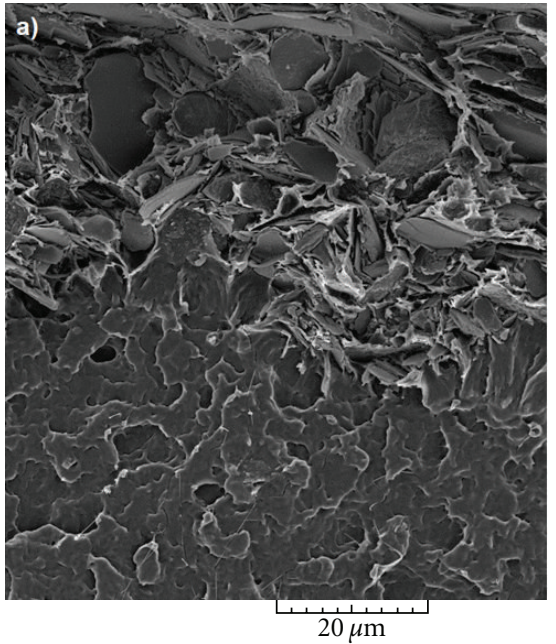

(a)

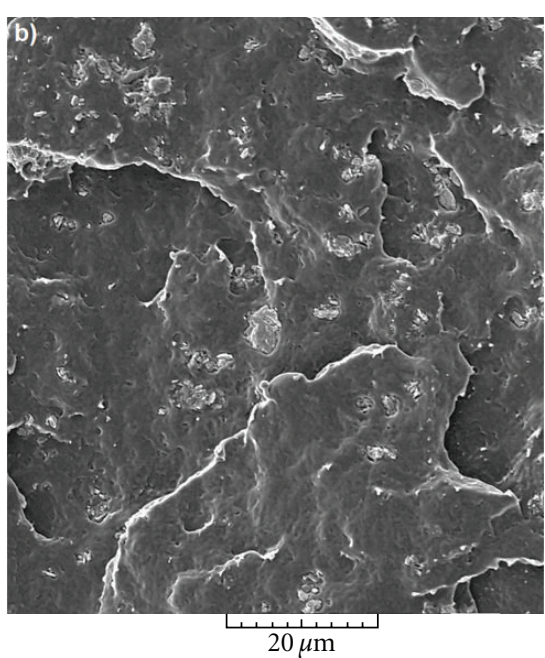

(b)

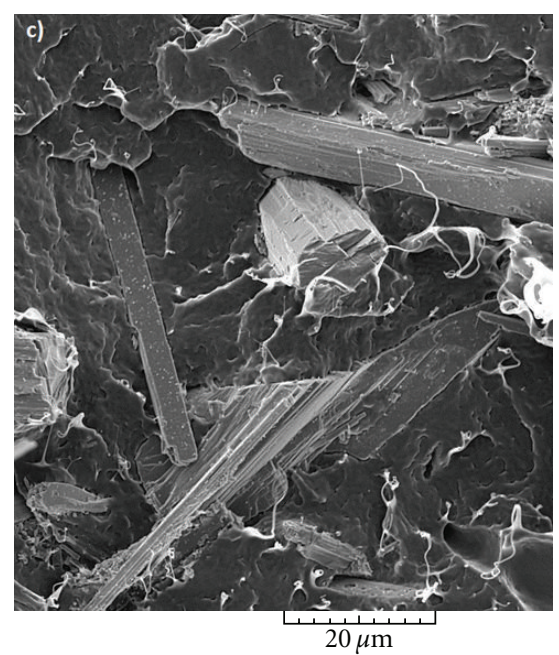

(c)

FIgURE 3: SEM micrographs of PLA-g-MDI composites filled with (a) Mica, (b) Zeolite, (c) Vansil.

TABLE 2: Storage moduli and factor C of PLA-g-MDI composites.

\begin{tabular}{lccc}
\hline Sample & $E^{\prime}$ at $20^{\circ} \mathrm{C}(\mathrm{MPa})$ & $E^{\prime}$ at $80^{\circ} \mathrm{C}(\mathrm{MPa})$ & Factor $C$ \\
\hline PLA-g-MDI & 3348 & 613 & 1 \\
PLA-g-MDI/Mica & 6041 & 1703 & 0.65 \\
PLA-g-MDI/Zeolite & 5010 & 1219 & 0.75 \\
PLA-g-MDI/Vansil & 4343 & 914 & 0.87 \\
\hline
\end{tabular}

TABLE 3: Damping characteristics of PLA-g-MDI composites.

\begin{tabular}{lccc}
\hline Sample & $\tan \delta$ intensity at peak & $\tan \delta$ temperature at peak $\left({ }^{\circ} \mathrm{C}\right)$ & Damping reduction $(\%)$ \\
\hline PLA-g-MDI & 0,233 & 77.3 & - \\
PLA-g-MDI/Mica & 0,258 & 80.8 & -10.5 \\
PLA-g-MDI/Zeolite & 0,207 & 77.3 & +11.1 \\
PLA-g-MDI/Vansil & 0,250 & 75.8 & -7.2 \\
\hline
\end{tabular}




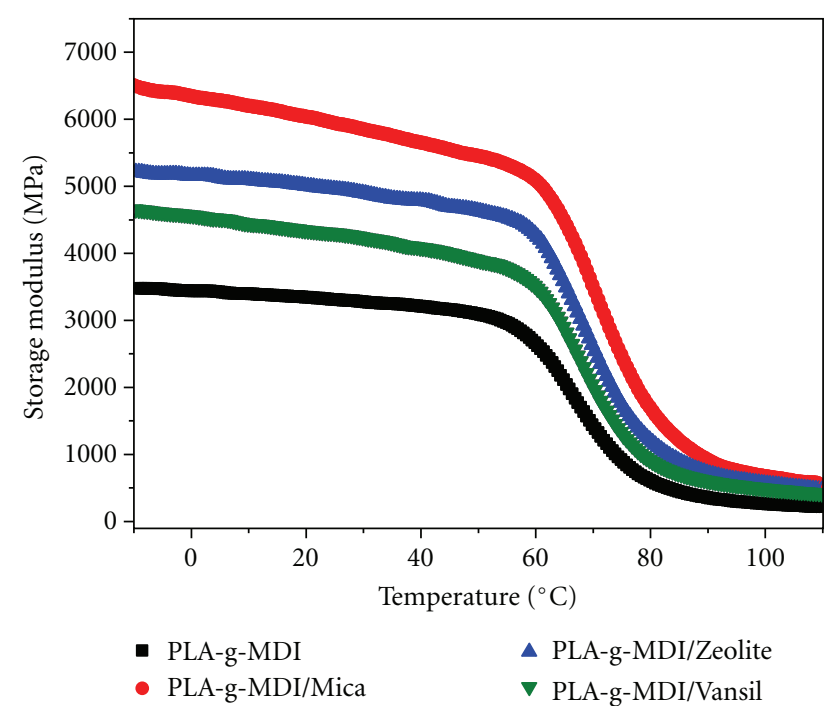

Figure 4: Storage moduli of PLA-g-MDI and PLA/mineral composites as a function of temperature. Frequency sweep was set at $1 \mathrm{~Hz}$.

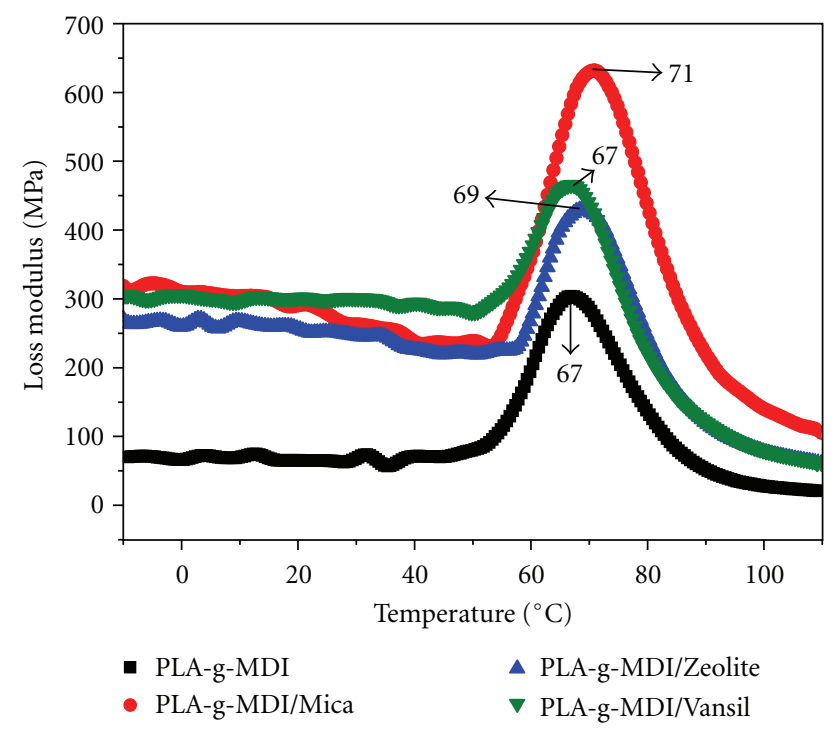

Figure 5: Loss moduli of PLA-g-MDI and PLA/mineral filler composites as a function of temperature. Frequency sweep was set at $1 \mathrm{~Hz}$; peak temperatures are outlined.

used mineral filler types. The fact that filler-filler friction due to broken agglomerates has contributed to the higher damping intensity can be used as an indicator for the filler distribution status. On the base of coherent observations of the filler distribution by both, the damping reduction and the SEM analysis, we conclude that DMA is a quick and reliable method to predict the functional morphology of PLA-based composites.

\section{Acknowledgments}

This work was supported by the Austrian Science Fund, FWF, through project L319-B16. The authors also acknowledge

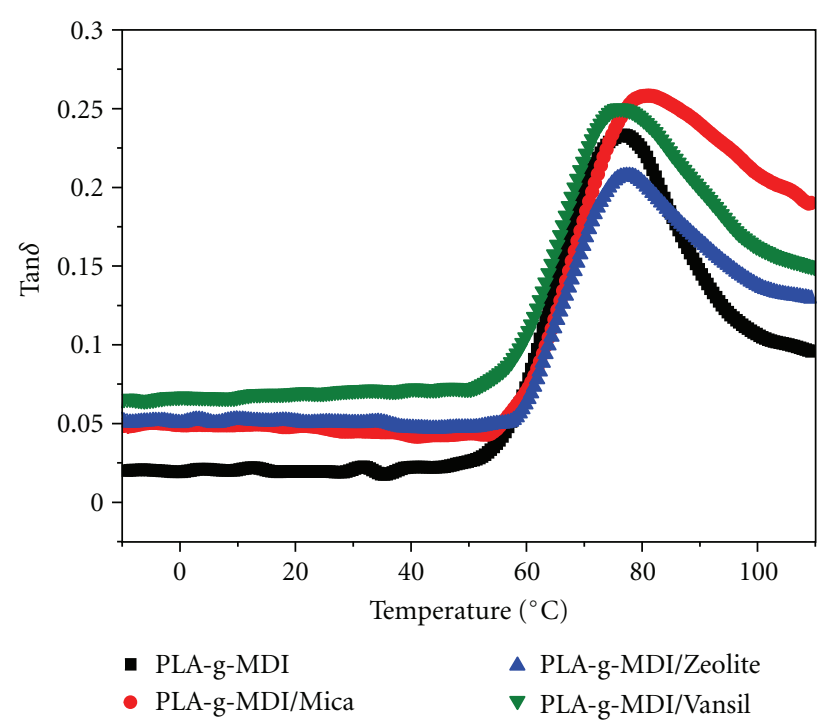

Figure 6: Damping factors $\tan \delta$ of PLA-g-MDI and PLA/mineral filler composites as a function of temperature. Frequency sweep was set at $1 \mathrm{~Hz}$.

support by the Austrian Agency for International Cooperation in Education and Research (OeAD-GmbH) (project no. WTZ 03/2011) and by the Ministry of Education, Youth, and Sports of the Czech Republic (Grant no. ME061102).

\section{References}

[1] E. T. H. Vink, K. R. Rábago, D. A. Glassner, and P. R. Gruber, "Applications of life cycle assessment to NatureWorks polylactide (PLA) production," Polymer Degradation and Stability, vol. 80, no. 3, pp. 403-419, 2003.

[2] G. Scott and D. M. Wiles, "Degradable hydrocarbon polymers in waste and litter control," in Degradable Polymers, G. Scott, Ed., Principles and Applications, pp. 449-479, Kluwer Academic, Dordrecht, The Netherlands, 2002.

[3] J. J. Kolstad, "Crystallization kinetics of poly(L-lactide-comeso-lactide)," Journal of Applied Polymer Science, vol. 62, no. 7, pp. 1079-1091, 1996.

[4] H. Urayama, C. Ma, and Y. Kimura, "Mechanical and thermal properties of poly(L-lactide) incorporating various inorganic fillers with particle and whisker shapes," Macromolecular Materials and Engineering, vol. 288, no. 7, pp. 562-568, 2003.

[5] H.-S. Kim, B. H. Park, J. H. Choi, and J.-S. Yoon, "Mechanical properties and thermal stability of poly(L-lactide)/calcium carbonate composites," Journal of Applied Polymer Science, vol. 109, no. 5, pp. 3087-3092, 2008.

[6] M. J. Sobkowicz, J. L. Feaver, and J. R. Dorgan, "Clean and green bioplastic composites: comparison of calcium sulfate and carbon nanospheres in polylactide composites," Clean, vol. 36, no. 8, pp. 706-713, 2008.

[7] N. Ignjatovic and D. Uskokovic, "Synthesis and application of hydroxyapatite/polylactide composite biomaterial," Applied Surface Science, vol. 238, no. 1-4, pp. 314-319, 2004.

[8] A. Gregorova, V. Sedlarik, M. Pastorek, H. Jachandra, and F. Stelzer, "Effect of compatibilizing agent on the properties of highly crystalline composites based on poly(lactic acid) 
and wood flour and/or mica," Journal of Polymers and the Environment, vol. 19, no. 2, pp. 372-381, 2011.

[9] J. Jancar, "Mineral fillers in thermoplastics," in Raw Materials and Processing, vol. 139 of Advances in Polymer Science, pp. 165, Springer, Berlin, Germany, 1999.

[10] C. Dupuy and P. Bussi, "New dispersion process for submicronic fillers in thermoplastics," Macromolecular Symposia, vol. 169, no. 1, pp. 103-107, 2001.

[11] T. Huuhilo, O. Martikka, S. Butylina, and T. Kärki, "Mineral fillers for wood-plastic composites," Wood Material Science and Engineering, vol. 5, no. 1, pp. 34-40, 2010.

[12] A. Gregorova, M. Hrabalova, R. Wimmer, B. Saake, and C. Altaner, "Poly(lactide acid) composites reinforced with fibers obtained from different tissue types of Picea sitchensis," Journal of Applied Polymer Science, vol. 114, no. 5, pp. 2616-2623, 2009.

[13] A. Gregorova, M. Hrabalova, R. Kovalcik, and R. Wimmer, "Surface modification of spruce wood flour and effects on the dynamic fragility of PLA/wood composites," Polymer Engineering and Science, vol. 51, no. 1, pp. 143-150, 2011.

[14] A. Gregorova, R. Wimmer, M. Hrabalova, M. Koller, T. Ters, and N. Mundigler, "Effect of surface modification of beech wood flour on mechanical and thermal properties of poly (3hydroxybutyrate)/wood flour composites," Holzforschung, vol. 63, no. 5, pp. 565-570, 2009.

[15] M. Hrabalova, A. Gregorova, R. Wimmer, V. Sedlarik, M. Machovsky, and N. Mundigler, "Effect of wood flour loading and thermal annealing on viscoelastic properties of poly(lactic acid) composite films," Journal of Applied Polymer Science, vol. 118, no. 3, pp. 1534-1540, 2010.

[16] J. F. Mano, "Study of the segmental dynamics in semicrystalline poly(lactic acid) using mechanical spectroscopies," Macromolecular Bioscience, vol. 5, no. 4, pp. 337-343, 2005.

[17] I. Spinu and G. B. McKenna, "Physical aging of nylon 66," Polymer Engineering \& Science, vol. 34, no. 24, pp. 1808-1814, 1994.

[18] L. H. Sperling, Introduction to Physical Polymer Science, John Wiley \& Sons, Toronto, Canada, 4th edition, 2006, Edited by L.H. Sperling.

[19] S. Farzaneh and A. Tcharkhtchi, "Viscoelastic properties of polypropylene reinforced with mica in $\mathrm{T}_{\alpha}$ and $\mathrm{T}_{\alpha \mathrm{c}}$ transition zones," International Journal of Polymer Science, vol. 2011, Article ID 427095, 5 pages, 2011.

[20] Y. Li, K. Venkateshan, and S. S. Xiuzhi, "Mechanical and thermal properties, morphology and relaxation characteristics of poly(lactic acid) and soy flour/wood flour blends," Polymer International, vol. 59, no. 8, pp. 1099-1109, 2010.

[21] N. C. Bleach, S. N. Nazhat, K. E. Tanner, M. Kellomäki, and P. Törmälä, "Effect of filler content on mechanical and dynamic mechanical properties of particulate biphasic calcium phosphate-polylactide composites," Biomaterials, vol. 23, no. 7, pp. 1579-1585, 2002.

[22] B. H. Li and M.-C. Yang, "Improvement of thermal and mechanical properties of poly(L-lactic acid) with 4,4-methylene diphenyl diisocyanate," Polymers for Advanced Technologies, vol. 17, no. 6, pp. 439-443, 2006.

[23] A. Gregorova and R. Wimmer, "Filler-matrix compatibility of poly(lactic acid) based composites," in Polylactic Acid: Synthesis, Properties and Applications, V. Piemonte, Ed., chapter 5, pp. 97-119, Nova Science, New York, NY, USA, 2012.

[24] S. Pattanawanidchai, P. Saeoui, and C. Sirisinha, "Influence of precipitated silica on dynamic mechanical properties and resistance to oil and thermal aging in CPE/NR blends," Journal of Applied Polymer Science, vol. 96, no. 6, pp. 2218-2224, 2005. 

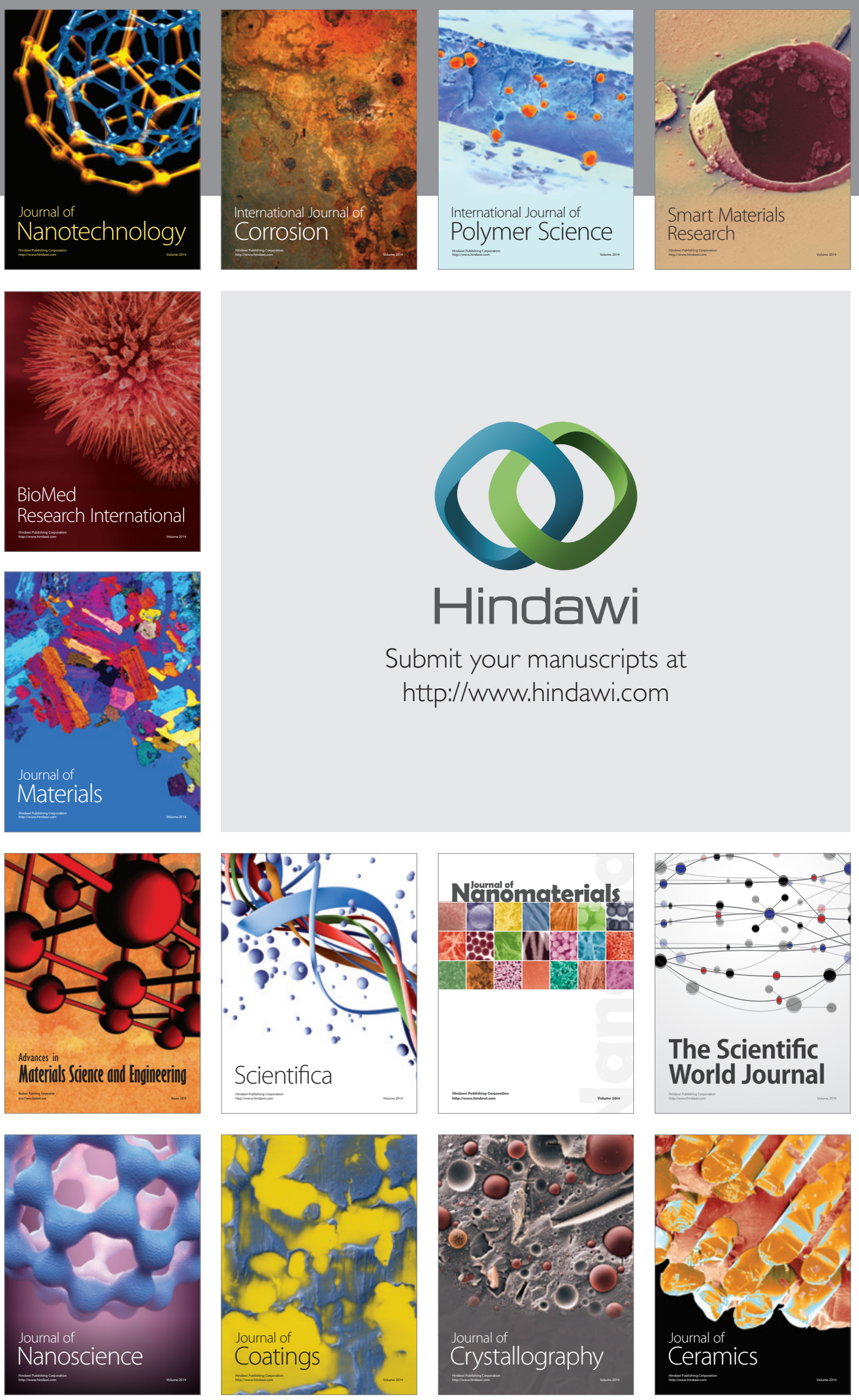

The Scientific World Journal

Submit your manuscripts at

http://www.hindawi.com

\section{World Journal}

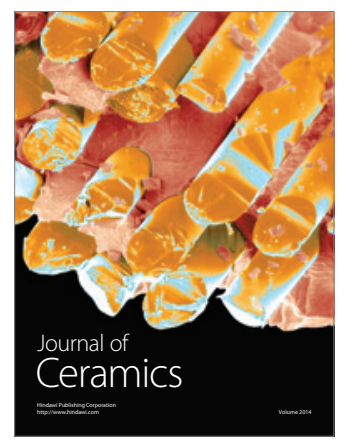

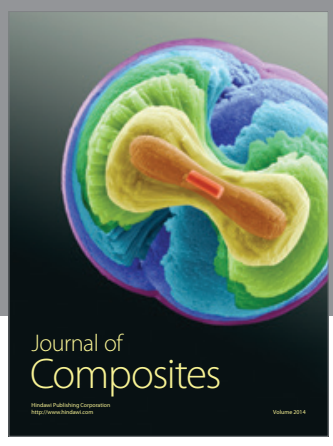
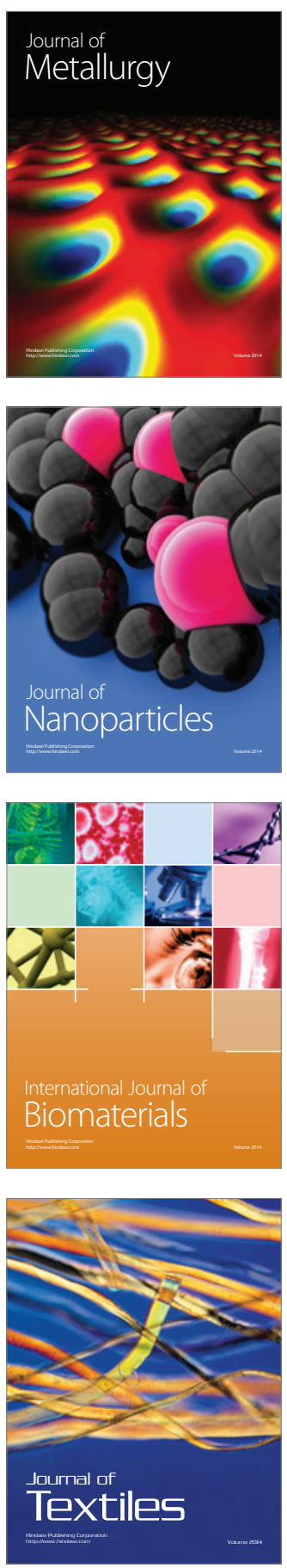